\title{
COM BENJAMIN POR UMA NOVA EPISTEMOLOGIA
}

Marden Moura Lopes

\begin{abstract}
RESUMO
O objetivo deste artigo visa explicitar como a filosofia benjaminiana elabora uma teoria do conhecimento cuja postura cinde com a matriz transcendental da teoria filosófica contemporânea. Por isso, ao assumir a tese de que toda Filosofia posterior a Kant recai na centralidade do sujeito transcendental e, por conseguinte, legitima o abismo que separa homem e mundo, demonstraremos, a partir das Questões Introdutórias de Crítica do Conhecimento, elaborada como uma Introdução à sua obra magistral Origem do drama Barroco Alemão, as posições benjaminianas sobre uma nova estruturação epistemológica, na qual o saber/conhecimento pode ser apreendido, dada sua múltipla diversidade, enquanto a verdade é inapreensível e autoapresentável.
\end{abstract}

Palavras-Chave: Epistemologia. História. Subjetividade transcendental. Verdade

\section{WITH BENJAMIN FOR A NEW EPISTEMOLOGY}

\begin{abstract}
This article aims to explain how the benjaminianna philosophy develops a theory of knowledge whose posture cut off with the transcendental matrix of homogeneous philosophical theory in his time. So, to take the view that all further Philosophy Kant lies in the centrality of the transcendental subject and therefore legitimizes the gap between man and world demonstrate from Knowledge Critical Introductory Questions, designed as a Introduction to his masterwork drama Source German Baroque, the benjaminianas positions on a new epistemological structure, in which the knowledge/knowledge can be captured, given their multiple diversity, while the truth is elusive and self presentable.
\end{abstract}

Key-Words: Epistemology. Historical. Transcendental subjectivity. Verity 


\section{Introdução}

Este artigo visa explicitar como a filosofia benjaminiana elabora uma teoria do conhecimento cuja postura cinde com a matriz transcendental da teoria filosófica homogênea à sua época. Por isso, ao assumir a tese de que toda Filosofia posterior a Kant recai, consciente ou inconscientemente, em maior ou menor grau, de uma forma ou de outra na centralidade do sujeito transcendental e, por conseguinte, legitima o abismo que separa homem e mundo - e esta tese alcança síntese clara nas elaborações de H. Putnam ${ }^{1}$ e K. -O. Apel (APEL, 240) -, procuraremos, compulsando as Questões Introdutórias de Crítica do Conhecimento, elaborada como uma Introdução à sua obra magistral Origem do drama Barroco Alemão, apresentar lato senso as posições benjaminianas sobre uma nova estruturação epistemológica.

Vale salientar que não obstante as teses Sobre o conceito da História (Über den Begriff der Geschichte ) - trabalho em que Benjamin parece revelar a teoria que acompanhou - apresentarem, de modo mais conciso, as críticas à teoria do conhecimento vigente - é claro, apeado em seus escritos anteriores - esse último trabalho não aparecerá em nossa discussão, pois nosso propósito visa explicitar uma possível teoria epistêmica na Introdução ao Origem do Drama do Barroco Alemão. E para não haver ambiguidade em nossa reflexão, de imediato declaramos que conscientemente não entraremos nessas tematizações, pois nosso objetivo é observar a mudança epistêmica no Trauerspielbuch. ${ }^{2}$

A orientação hipotética de nossa reflexão segue, em linhas gerais, as considerações de Gagnebin, para a qual o prefácio introdutório "marca a despedida de Benjamin do ideal de sistema do idealismo alemão, em particular do sistema kantiano, perfazendo assim o movimento de afastamento progressivo de Kant que Benjamin iniciou no seu ensaio de 1917, Sobre o programa de uma filosofia futura.

\footnotetext{
${ }^{1}$ Cf. (PUTNAM, 1996, p. 210).: "Kant may have been overambitious...but the idea that all experience involves mental construction, and the idea that the dependence of physical object concepts and experience concepts goes both ways, continue to be of great importance in contemporary philosophy (of many varieties)".

2 Dois argumentos que reforçariam a proposta de elaboração frente a essa obra: 1- a pasta onde Benjamin guardava os rascunhos das teses estava intitulada "Conhecimento Teórico, Teoria do Progresso"; 2- numa de suas cartas a Horkheimer, Benjamin diz que seus trabalhos sobre a história e o progresso "não podem não ter consequências para a teoria do conhecimento". (MATE, 2011. p. 20)

Mestrando em Filosofia no CMAF na Universidade Estadual do Ceará (UECE). Professor de Filosofia do Colégio Christus-CE. Residente em Fortaleza - CE. Email: mardenmoura@hotmail.com
} 
[...]; significa, a reivindicação de uma outra possibilidade de fazer filosofia" (GAGNEBIN, 2005, 189-190).

Uma vez que a filosofia transcendental marca o paradigma da Filosofia ao tematizar o universo categorial do sujeito, ou seja, as condições de possibilidade e validade do conhecimento, ela engessa em diferentes formulações a tarefa da Filosofia e mais precisamente da Antropologia Filosófica. Como resultado imediato dessa postura temos a redução da esfera do conhecimento aos fenômenos como única experiência possível, uma vez que tudo o que nos é dado tem que ser dado na intuição sensível (KANT, 1997, p. XIX-XX). A experiência da coisa em si - do noumeno ${ }^{3}$ - não é possibilitada, dado o aparato cognoscível da esfera antropológica. Com isso, temos um segundo resultado, a saber, conhecemos somente o que aparece (Erscheinung) para nós pela mediação fenomênica, a realidade em si não pode ser alcançada por nós. Essa redução da experiência deixa de fora toda realidade e o homem emerge separado da experiência histórica e das vicissitudes mundanas. Aqui se legitima a verdade na esfera da relação sujeito e fenômeno, entretanto o sujeito aparece como determinante nessa relação uma vez que ele instancia seu conhecimento a priori dos fenômenos. A verdade é um ser indefinível. A verdade é a morte da intenção (BENJAMIN, 1984, 58)

Walter Benjamin elabora a distinção entre a posse do saber e a verdade em Questões Introdutórias de Crítica do Conhecimento ${ }^{4}$, não obstante o caráter esparso de suas tematizações ele assevera como o saber pode ser obtido na consciência enquanto a verdade, dada sua multifacetariedade, esquiva-se a qualquer tentativa de apropriação (BENJAMIN, 1984, 49).

\footnotetext{
${ }^{3}$ Cabe-nos aqui assegurar aos leitores nossa consciência das diversas interpretações sobre coisa em si e noumeno na filosofia de Kant, especificamente na Crítica da Razão Pura, entretanto tomamos por "sinônimos" apenas para designar, aqui, o que separa a esfera da dimensão cognoscível o fenômeno e a esfera da dimensão incognoscível que, de um modo ou de outro, já aparecem na coisa em si e, consequentemente, no noumeno. Cf. (LOUZADO, 2006, p. 149-164). Também o bem articulado trabalho de BONACCINI, Juan Adolfo. Acerca do conceito de fenômeno na Crítica da Razão Pura. In. Princípios, Ano 04, n 05, 1997. p. 159-186.

4 "Como Adorno fez mais tarde em "Ensaio como forma", Benjamin reivindica a possibilidade de definir a atividade filosófica de maneira diferente daquela segundo as regras do método cartesiano. Não contesta, porém, a grandeza do empreendimento cartesiano, não polemiza contra Descartes, como fará Adorno, mas relembra a existência de outra tarefa para a filosofia, tarefa descartada ou condenada pela maior parte da filosofia moderna, desde Descartes e até hoje: pensar filosoficamente não é única e exclusivamente conhecer ou refletir sobre as condições e possibilidades do conhecimento humano. O "Prefácio" marca a despedida de Benjamin do ideal de sistema do idealismo alemão [...]". (GAGNEBIN, 2016, p. 186).
}

Mestrando em Filosofia no CMAF na Universidade Estadual do Ceará (UECE). Professor de Filosofia do Colégio Christus-CE. Residente em Fortaleza - CE. Email: mardenmoura@hotmail.com 
Contudo, nossa reflexão visa aprofundar a crítica do conhecimento que repousa sobre o conceito de saber epistemologizado, que em meio a diversas delineações se encontram sistematizadas em Kant. Por isso, de acordo com Benjamin o equívoco kantiano, que consistiu em deixar aberto o conceito de conhecimento referente ao programa da razão pura, deu margem a uma interpretação tendenciosa por parte dos neokantianos, em especial, de Hermann Cohen e Heinrich Rickert. Esses, reelaborando as tematizações kantianas, teriam reduzido ainda mais a abrangência da definição de Kant do conhecimento, ao acentuarem consideravelmente o lado mecânico-empírico e vazio do conceito em questão. Disso resultou a compreensão da ideia de experiência em Kant como sendo idêntica a das ciências modernas, o que fadaria a experiência filosófica (MURICY, 1999, 73).

\section{A consciência de uma epistemologia adequada à indefinição}

Seria interessante ressaltar que a diversidade natural do mundo exige uma filosofia que possa reagir a riqueza dessa complexidade. Por isso é coerente substituir a palavra "incompleta" por "indefinição". No entanto a consciência disso tem que ser a mais precisa possível, e não assistemática.

Podemos, de início, sustentar que Benjamin não segue a tradição da filosofia moderna na medida em que despotencializa a subjetividade e funda seu pensamento na construção de imagens com palavras, conforme argumenta Barrento

[...] um pensamento reverberante, em trânsito, rizomático, servido por um método em que se cruzam a fenomenologia e a hermenêutica crítica (ou a "crítica filosófica", como ele próprio prefere dizer), o marxismo e o messianismo, para levar à prática, na leitura que faz dos mais diversos objectos, uma verdadeira quadratura do círculo: encontrar o corpo da ideia, materializar a metafísica. Como? Pelo seu pensamento imagético (e não apenas conceitual), e pela sua determinação em evitar o que chamava, em carta a Hofmannsthal de 13 de janeiro de 1924, "a barbárie da linguagem das fórmulas", e a que contrapõe a necessidade de libertar as palavras da "carapaça dos conceitos" pela "força magnética do pensar".(BARRENTO, 2012, 51)

Com isso o filósofo entende que "a unidade do saber, se é que ela existe, consiste apenas numa coerência mediata, produzida pelos conhecimentos parciais e de certa forma por seu equilíbrio, ao passo que na essência da verdade a unidade é Mestrando em Filosofia no CMAF na Universidade Estadual do Ceará (UECE). Professor de Filosofia do Colégio Christus-CE. Residente em Fortaleza - CE. Email: mardenmoura@hotmail.com 
uma determinação direta e imediata" (BENJAMIN, 1984, 52), entretanto "Como unidade no Ser, e não como unidade no Conceito, a verdade resiste a qualquer interrogação" (BENJAMIN, 1984, 52). Assim "o que diferencia a filosofia benjaminiana da tradição moderna é o seu "modo de concentração": a valorização da exterioridade, que se faz em um movimento de evasão, de entrega total às minúcias da realidade concreta onde a intenção subjetiva se apaga" (CASTRO, 2009, 208).

Destarte, o que surge em relação à subjetividade, entendida aqui no sentido transcendental kantiano, no projeto filosófico benjaminiano, é que o homem não se reduz a seu saber, antes ele é uma dimensão da verdade que escapa a qualquer determinação, pois enquanto a filosofia transcendental engendra a Filosofia numa doutrina dogmática e, por conseguinte, o homem se torna instância doadora de sentido a tudo, ao projeto benjaminiano de Filosofia assegura o caráter multifacetário da verdade e das inúmeras possibilidades do homem se reestruturar, não é algo fechado e entregue ao domínio antropológico (BENJAMIN, 1984, 69).

Aqui entra em jogo, é claro, o estatuto antropológico da filosofia de Benjamin o qual busca, em contraposição ao determinismo das ciências, uma formação do homem em sua integralidade. Por isso, vale assegurar que as antropologias são autenticamente humanas ou não são antropologias, e em sua autenticidade humana se joga o valor eminentemente Filosófico. Vincular o homem à uma determinada antropologia procurando identifica-lo com ela é negar ou suprimir, consciente ou inconscientemente, as diversas formas, por vezes contraditórias, em que o homem vai desenvolvendo sua existência; entretanto, quando se quer ampará-lo com o qualitativo de "Eu" transcendental e com isso delinear os traços de uma antropologia universal deve-se assumir como pano de fundo um recurso ideológico para excluir a convivência ou a concorrência de outras ideologias que não tem uma visão transcendental do homem, o contrário também é verdadeiro.

Quando Marx afirma que a realidade do homem não coincide com sua verdade e chama essa dissociação de "alienação" humana, ou quando Hegel infere que o natural não se identifica com o humano e que é humano que o humano deixe de ser natural, situam-se ambos naquelas linhas que apontamos acima, ou seja, que interpreta a partir daquilo que apreende do homem, todavia não são capazes de 
assinalar este homem como um ser de tensão e contradição: um ser finito com possibilidades infinitas. Daí Benjamin defender a tese de que não é necessário a este homem ajustar-se a condutas razoáveis e evitar as menos razoáveis ${ }^{5}$, pois o pretendido proveito da racionalidade da conduta emerge como medo de não ser capaz de voar. Logo, a racionalidade é antes uma forma de se camuflar frente às diversas possibilidades da vida humana.

A tentativa de Benjamin visa reencontrar uma elaboração inicial da filosofia que cinde com os determinismos epistemológicos da "reviravolta copernicana". A incessante busca de Benjamin por um novo conceito de experiência resume-se, na verdade, à tentativa de definir e distinguir um tempo e um espaço simultaneamente diferente desse que se apresentaria ao indivíduo moderno, do sujeito furtado de experiência tal qual se entende esse conceito na modernidade, pobre - tal como assinala em seu ensaio de 1933, Experiência e Pobreza -; em suma, um indivíduo alheio ao espaço-tempo, multidimensional, diverso, não homogêneo e nem vazio. Eis a analogia que Benjamin faz da mônada leibniziana ${ }^{6}$. Esta não tem fenestras para estabelecer comunicação com as demais mônadas, entrementes, apesar de diferentes, possuem a mesma essência, haja vista que cada uma delas possui dentro de si todas as possibilidades relativas à sua existência (MEDEIROS, 2010, 49). Assim "O saber visa o particular, mas não a unidade desse particular" (BENJAMIN, 1984, 52).

A querela de inferências que vimos elaborando desemboca na afirmação inconcussa de que esse sujeito kantiano não pode chegar ao conhecimento ou apreender o saber de modo absoluto, pois o emprego metódico da razão é apenas

\footnotetext{
${ }^{5}$ Observe-se que essa expressão menos razoáveis não tem a conotação de condutas irracionais, pois a irracionalidade é o sinônimo dos grades sistemas totalitários.

6 Segundo Benjamin: "a estrutura dessa ideia, resultante do contraste entre seu isolamento inalienável e a totalidade, é monadológica. A ideia é mônada. O ser que nela penetra com sua préhistória traz em si, oculta, a figura do restante do mundo das ideias, da mesma forma que segundo Leibniz, em seu Discurso sobre a Metafísica, de 1686, em cada mônada estão indistintamente presentes todas as demais. A ideia é mônada - nela reside, preestabelecida, a representação dos fenômenos, como sua interpretação objetiva. Quanto mais alta a ordem das ideias, mais completa a representação nelas contida. Assim o mundo real poderia constituir uma tarefa, no sentido de que ele nos impõe a exigência de mergulhar tão fundo em todo real, que ele possa revelar-nos uma interpretação objetiva do mundo" (BENJAMIN, 1984, p.70). A interconexão estabelecida por Benjamin visa salvaguardar a autonomia das ideias, sua anterioridade em relação aos fenômenos e sua dimensão microcósmica, no entanto há uma superação do paradigma platônico na medida em que se assume a compreensão monadológica das ideias, seu relacionamento com tudo; sem estas considerações compreensão do pensamento de Benjamin se torna ininteligível.
}

Mestrando em Filosofia no CMAF na Universidade Estadual do Ceará (UECE). Professor de Filosofia do Colégio Christus-CE. Residente em Fortaleza - CE. Email: mardenmoura@hotmail.com 
uma forma de conhecimento e de longe é abrangente, não é irrelevante o fato de que Benjamin, na introdução chamada "Questões Introdutórias de Crítica do Conhecimento", mostra como é seu parecer sobre a escrita filosófica, uma escrita que deveria ser expositora, apresentando seus objetos. Na verdade, ele está indo contra uma espécie de preceito linguístico, instintivamente transcendental, que diz que as coisas são separadas do sujeito, onde o fenômeno é o único possibilitante do conhecimento, do saber. A coisa em si (noumeno) é absolutamente inapreensível, incognoscível, como se o mundo real fosse absolutamente inacessível ao sujeito, afirmação não mais verdadeira que a seguinte: o sujeito está separado do mundo, pois há um abismo epistemológico que os separa. $O$ homem sente-se senhor do saber acerca dos fenômenos, mas não percebe sua nítida impossibilidade de conhecer o mundo na sua realidade.

A modernidade e com ela seu modus operandi transcendental está em crise, por isso ao se colocar contra o progresso se evidencia a decadência dessa operação transcendental e por essa razão Walter Benjamin afirma que "o universo do pensamento filosófico não se desenvolve pela sequência ininterrupta de deduções conceituais, mas pela descrição do mundo das ideias" (BENJAMIN, 1984, 65). Não obstante as ruínas conjecturais da modernidade, esse novo modus operandi que Benjamin está estruturando propõe a decadência de um único método para a pesquisa filosófica tendo em vista que para ele é importante não perder de vista que também o "método é caminho indireto, é desvio. A representação metodológica como desvio é, portanto a característica metodológica do tratado" (BENJAMIN, 1984, 50), sendo assim:

Para que a verdade seja representada em sua unidade e em sua singularidade, a coerência dedutiva da ciência, exaustiva e sem lacunas, não é de nenhum modo necessária. E no entanto essa exaustividade sem lacunas é a única forma pela qual a lógica do sistema se relaciona com o conceito de verdade. Essa sistematicidade fechada não tem mais a ver com a verdade que qualquer outra forma de representação. ${ }^{7}$ (BENJAMIN, 1984, 55)

\footnotetext{
${ }^{7}$ O termo representação deve ser observado segundo as considerações de GAGNEBIN (que nossos interlocutores não fizeram e por isso urge a necessidade de esclarecimento), segundo ele: "O primeiro mal-entendido a ser dirimido é uma questão de tradução. A palavra Darstellung — utilizada por Benjamin para caracterizar a escrita filosófica - não pode, (aliás, nem deve), ser traduzida por "representação", como o faz Rouanet (que compreendeu perfeitamente o alcance do texto, conforme sua "Apresentação" muito esclarecedora demonstra, mas que o traduziu, às vezes, de maneira pouco Mestrando em Filosofia no CMAF na Universidade Estadual do Ceará (UECE). Professor de Filosofia do Colégio Christus-CE. Residente em Fortaleza - CE. Email: mardenmoura@hotmail.com
} 
Haja vista que a posição benjaminiana se impõe sobre a sistematicidade fechada, emerge dessa proposta um esquema assistemático de Filosofia que se articula na mutabilidade do mundo, na variabilidade dos conjuntos do conhecimento e dos meros conhecimentos.

A Filosofia deve ser fiel a sua formulação inicial que há mais de dois mil anos se definiu a si mesma como um saber que se pretendia abrangente, o que não significa, em detrimento das formulações posteriores, uma absolutização deste saber, antes, como uma guia para o conhecimento das mais diversas formas da realidade, articulava os nexos inelimináveis de uma teoria da verdade. O objetivo fundamental da Filosofia se revela com a pretensão de ser ciência universal, não no sentido que o homem venha a deter tal conhecimento, mas no sentido de que somente pela ótica da Filosofia o mundo como um todo pode ser visto de maneira coerente, assim a Filosofia, antes de ser uma Filosofia totalitária, é ao mesmo tempo um princípio de conexão de tudo e do todo enquanto princípio de heterogeneidade : "A verdade é o equilíbrio tonal das essências". Sendo assim é então o arcabouço estrutural da filosofia ${ }^{8}$.

Se o contrário absoluto desta tese é assumido por qualquer filosofia a ciência assumirá uma ideologia que não é mais capaz de refletir crítica e cientificamente sobre si mesma se pondo a serviço de determinados interesses societários, cujo objetivo é manifestar que o interesse básico da Teoria Crítica é tematizar os interesses da sociedade moderna e legitimá-los sobre um prisma totalitário. $\mathrm{O}$ elemento decisivo para o desenvolvimento do pensamento filosófico é sua dimensão

precisa), nem o verbo darstellen pode ser traduzido por "representar". Mesmo que essa tradução possa ser legítima em outro contexto, ela induz, no texto em questão, a um contra senso, porque poderia levar à conclusão de que Benjamin se inscreve na linha da filosofia da representação quando é exatamente desta, da filosofia da representação, no sentido clássico de representação mental de objetos exteriores ao sujeito, que Benjamin toma distância. Proponho, então, que se traduza Darstellung por "apresentação" ou "exposição", e darstellen por "apresentar" ou "expor", ressaltando a proximidade no campo semântico com as palavras Ausstellung (exposição de arte) ou também Darstellung, no contexto teatral (apresentação)" (GAGNEBIN, 2016, p. 184). Entretanto, tendo claramente a distinção, manteremos as citações tal qual foram formuladas na tradução de língua portuguesa à qual dispomos.

8 "Se a filosofia quiser permanecer fiel à lei de sua forma, como representação da verdade e não como guia para o conhecimento, deve-se atribuir importância ao exercício dessa forma, e não à sua antecipação, como sistema" (BENJAMIN, 1984, p. 50). (referente à palavra representação nesta citação e em outras deixamos na tradução tal como se encontra, entretanto leve-se em consideração a nota anterior, o que nos lança ao entendimento de apresentação)

//

Mestrando em Filosofia no CMAF na Universidade Estadual do Ceará (UECE). Professor de Filosofia do Colégio Christus-CE. Residente em Fortaleza - CE. Email: mardenmoura@hotmail.com 
veritativa que não é apreendida, resultando assim nas diversas formas de enxergar o mundo. Fugir deste caráter é adentrar numa espécie de postura não filosófica onde há uma fusão entre técnica e dominação, racionalidade e opressão que impede a articulação de uma teoria filosófica mais verdadeira no sentido de que não se reduz a um determinado modo de agir racionalmente, pois "o procedimento próprio à verdade não é uma intenção voltada para o saber, mas uma absorção total nela, e uma dissolução. O totalitarismo pode ser apresentado na perspectiva de sistema, pois há um vínculo que orienta as duas dimensões, a saber, ambas são incapazes de vislumbrar a beleza da singularidade das diferenças, das contradições, esse caráter central atesta como corolário de sua afirmação que ambos

\begin{abstract}
visam o ensino dogmático do indivíduo, transmitindo a ele informações ideológicas, ocasionando a sua instrumentalização e a transformação do indivíduo em massa. No momento em que o homem recebe passivamente um discurso baseado em um pseudo-universal, ele se torna mera ferramenta incapaz de autoreflexão. A ideologia por ele adquirida é agora reproduzida de maneira não problematizadora. (MEDEIROS, 2010, 26)
\end{abstract}

Frente a este novo modo de olhar para o mundo, a razão erigida sobre o cimo da epocalidade moderna ${ }^{9}$ e sublimada pela técnica e epistemologização das ciências começa a ser questionada em referência à sua dominação, a ideologia que era velada com a venda dos totalitarismos e dos pseudo-progressos vinham paulatinamente à tona e sua realidade começava a se diluir ao passo que era conhecida. Essas tematizações engendraram, acima de tudo, um olhar carregado de esperança, que acreditava no poder de luta e de recriação de um ser humano inconformado ao perceber que fora enganado, vendado e explorado.

A composição da totalidade exige de imediato uma ruptura com a temporalidade. Na verdade, é necessário fazer com que se dissipem os totalitarismos para que os objetos do conhecimento possam ser conhecidos e a verdade representada, pois só no "agora do cognoscível" é possível atingir o surgimento da representação da verdade, a partir disso, entra em jogo um tempo

\footnotetext{
${ }^{9} \mathrm{~A}$ incessante procura pela novidade é uma característica essencial para se entender o que é o moderno para Benjamin. Jeanne-Marie Gagnebin utiliza um termo que sugere a dialética autodestrutiva da modernidade na medida em que essa engessa as novidades posteriores e se internaliza como último horizonte filosófico, a saber: novidade fugaz. "o novo está, por definição, destinado a transformar-se no seu contrário, no não mais novo, no obsoleto e no envelhecido" (GAGNEBIN, 1994. p. 48).
}

Mestrando em Filosofia no CMAF na Universidade Estadual do Ceará (UECE). Professor de Filosofia do Colégio Christus-CE. Residente em Fortaleza - CE. Email: mardenmoura@hotmail.com 
histórico autêntico, conforme argumenta Benjamin: "Todo presente é determinado por aquelas imagens que lhe são sincrônicas: cada agora é o agora de uma determinada cognoscibilidade. Nele, a verdade está carregada de tempo até o ponto de explodir" (BENJAMIN, 2006, 504-505), gerando assim novos tempos em que existem novas cognoscibilidades, novas formas de entendimento, de conceituação, de expressividade e, por conseguinte, novas representações da verdade. Daí se segue o caráter flugidio dessa verdade que escapa a quaisquer determinações humanas, porque "a estrutura da verdade requer uma essência que pela ausência de intenção se assemelha à das coisas, mas lhes é superior pela permanência" (BENJAMIN, 1984, 58). Um argumento central para o filósofo nesse momento é que a mudança de significado dos termos teóricos em que se apeavam a verdade e o saber/conhecimento são reposicionados na medida em que se põe o sujeito que conhece, na história, fazendo assim emergir o saber como dimensão apreendida e desdobrada pelas ciências enquanto a verdade é sempre uma construção inacabável e apresentada na história e jamais uma apreensão universal ou transcendental.

Então, frente a esta querela moderna, como podemos apontar, em linhas gerais, sua estruturação epistemológica? Para começar a falar, devemos salientar que em Benjamin não existe uma proposta que desagregue todas as outras, não obstante, o conceito em sua estruturação teórica exerce duas funções chave: 1- em relação aos fenômenos o conceito tem a tarefa de resguardá-los da dominação subjetiva dos indivíduos; 2- em relação às ideias, representá-las de maneira objetiva. O conceito é mediador, entretanto em seu sentido mais geral é inteiramente indeterminado ou subdeterminado, porque ele é um medior, o que aqui constitui sua única determinidade, uma vez que o medior nesse nível é capaz de dar algo a conhecer e deixá-lo completamente fora do império dogmático subjetivo, resguardando assim sua verdade, mas também sem deixar de revelá-la, representála. Conforme Benjamin argumenta "A redenção dos fenômenos por meio das ideias se efetua ao mesmo tempo que a representação das ideias por meio da empiria. Pois elas não se representam em si mesmas, mas unicamente através de um ordenamento de elementos materiais no conceito, de uma configuração desses elementos" (BENJAMIN,1984, 56). 
$\mathrm{Na}$ esteira de Platão (e, igualmente, na da crítica hegeliana a Kant), Benjamin insiste na legitimidade de uma outra prática do pensar filosófico: um acompanhar pelo pensar e pela Vernunft a auto-exposição da verdade. Ou ainda: Benjamin recorre a filosofemas pré-kantianos, sim, mas não porque teria uma recaída fatal na ontologia realista. Devemos, nesse contexto, nos guardar de interpretar as "ideias" de Benjamin como seres supra-sensíveis e ontologicamente primeiros, como em Platão. Se retomarmos a leitura muito peculiar que Benjamin faz do Banquete nesse "Prefácio", podemos entender melhor seu recurso a conceitos platônicos sem postular a mesma ontologia. Segundo as interpretações correntes, o Eros platônico aspira ao belo (moço!) e à beleza, porque a beleza representaria a Verdade, existiria como um reflexo sensível do Bom e Verdadeiro em si que é puramente inteligível. Benjamin lê o Banquete de maneira muito mais ousada. Se se pode dizer da verdade que ela é o "teor essencial da beleza ("Wesensgehalt der Schönheit"), isso também significa que o Banquete "declara que a verdade é bela" ("erklärt die Wahrheit für schön"). Não só a beleza é redimida de sua tendência a somente pertencer ao domínio do brilho (Schein) e da aparência (Erscheinung, Schein) pela sua última ligação à verdade; também esta, a verdade, precisa por assim dizer, da beleza para ser verdadeira: a verdade não pode realmente existir sem se apresentar, se mostrar e, portanto, aparecer na história e na linguagem. Não há, então, subsunção da beleza à verdade em uma hierarquia ontológica que submete o sensível ao inteligível e o aparecer ao ser. Entre verdade e beleza haveria uma relação de co-pertencimento constitutivo como entre essência e forma: como forma da verdade, a beleza não pode se contentar em brilhar e aparecer, se quiser ser fiel à sua essência, à verdade; e, reciprocamente, como essência da beleza, a verdade não pode ser uma abstração inteligível "em si", sob pena de desaparecer, de perder sua Wirklichkeit (realidade efetiva). Somente pode ser real enquanto exposição e apresentação de si através da beleza: "No interior da verdade, esse momento de exposição é o refúgio da beleza em geral" ("In der Wahrheit ist jenes darstellendes Moment das Refugium der Schönheit überhaupt"). (GAGNEBIN, 2005, 189-190)

Se esta consideração a respeito da conceituabilidade filosófica é levada a sério na teoria do conhecimento, a articulação das contraposições epistemológicas sujeito e objeto são também reestruturadas, pois dada a possibilidade cognoscitiva do mundo tal como ele é, uma ideia objetiva e não um fenômeno apreendido em sua absoluta estrutura, é ao mesmo tempo salvaguardado aqui a verdade absoluta que é auto-expositiva, uma vez que a ideia é conceitualizada pela empiria. Esse processo, todavia, acontece não mais entre um sujeito destituído da História e doador de sentido a tudo, mas a um sujeito que junto ao mundo é assinalado como portador de uma história, de uma linguagem, numa palavra, um sujeito mundano. Portanto, no mundo vivido com suas mazelas e riquezas, o conhecimento se efetiva e a verdade vai se apresentando como um mosaico interminável, composto pela rica complexidade das diferenças, no lugar de um único sujeito como imaginava do Colégio Christus-CE. Residente em Fortaleza - CE. Email: mardenmoura@hotmail.com 
Descartes para realizar uma construção perfeita. As diferenças é que fazem a "beleza do todo plástico", por isso a Filosofia não pode mais ser indiferente a elas:

\begin{abstract}
Tanto o mosaico como a contemplação justapõem elementos isolados e heterogêneos, e nada manifesta com mais força o impacto transcendente, quer da imagem sagrada, quer da verdade. O valor desses fragmentos de pensamento é tanto maior quanto menor sua relação imediata com a concepção básica que Ihes corresponde, e o brilho da representação depende desse valor da mesma forma que o brilho do mosaico depende da qualidade do esmalte. (BENJAMIN, 1984, 51)
\end{abstract}

Benjamin elabora, dessa forma uma nova concepção de totalidade. Ela é elaborada a partir da diversidade e da complexidade, a maneira de um mosaico medieval, constituído de fragmentos de nuanças, matizes e tamanhos diferentes, e não de formas estéreis na sua simetria. Esse novo modelo de totalidade exige a acuidade e a percepção treinada do filósofo e artista que para Benjamin constitui uma só unidade: “ ...”a relação entre o trabalho microscópico e a grandeza do todo plástico e intelectual demonstra que o conteúdo de verdade só pode ser captado pela mais exata das imersões nos pormenores do conteúdo material. Em sua forma mais alta, no Ocidente, o mosaico e o tratado pertencem à Idade Média. Sua comparação é possível, porque sua afinidade é real" (BENJAMIN, 1984, 51).

Por isso, "Filosofia e arte, cada uma a seu modo, elaboram e inventam as formas linguísticas e históricas nas quais essa "verdade" imanente ao sensível e ao tempo, nasce, aparece e desaparece" (GAGNEBIN, 2005, 190). Nesse trecho se nota que "o reconhecimento de que a filosofia institucional era excessivamente formalista e vazia de verdade leva Benjamin a valorizar a linguagem do artista" (D' ANGELO, 2006, 23). A dimensão daquela coisa em si kantiana inacessível ao entendimento porque estava cindida pelo abismo subjetividade - mundo, para Benjamin está bem onde os sentidos não haveriam de trair o homem, no devir inconteste da materialidade conhecida em sua ideia e representada veritativamente pelo conceito (GAGNEBIN, 2005, 190), pois estes "dissolvem as coisas em seus elementos constitutivos" (BENJAMIN, 1984, 56). Teoricamente nada obsta a afirmação de que esta posição é uma teoria crítica da Filosofia e de sua do Colégio Christus-CE. Residente em Fortaleza - CE. Email: mardenmoura@hotmail.com 
epistemologização, ela visa salvar o homem do que posteriormente ficou conhecido como declínio da razão.

\section{Considerações finais}

O pressuposto que Benjamin introduz frente às posições conflitantes da tradição moderna do sujeito transcendental com sua nova proposta epistêmica é que nossa compreensão mundividente não é produto de nossa consciência, antes é algo que ocorre em nós como homens-criaturas do mundo.

Portanto, a consciência transcendental, ou subjetividade, não é o fenômeno originário e a condição de possibilidade de nosso estar no mundo, como queria Kant; muito menos se nos apresenta como o princípio único, fundamental e ineliminável do pensar e do agir sobre o mundo, ela não é centro de referência de tudo, o que constituía a tese básica de toda filosofia mentalista moderna. Para Benjamin a problematização de nós mesmos enquanto subjetividade é importante, mas é secundária. Uma vez que a subjetividade já traz sempre de alguma forma a uma determinação ulterior e mais abrangente, algo que está além dela. Na medida em que as posturas benjaminianas vão sendo aceitas, ocorre-nos aceitar também que na medida em que a subjetividade capta-se a si mesma, mostra sua dependência de algo o qual não pode engendrar por si mesma, muito menos dominar com suas logicizações.

$E$ isto constitui a experiência fundamental do ser humano, a experiência de não ser o fundamento de si. Nesse sentido poderíamos, analogamente, inferir que esse ser humano que não é experiência fundamental de si extrapola os limites de seu ego e instaura-se no a priori histórico de sua época não para se conformar com ele, mas para dar novo sentido a este momento aprendendo a conhecer e apreendendo o saber, entretanto sem jamais deter absolutamente a verdade (BENJAMIN, 1984, 61).

Todavia, ao ir compreendendo que a fluidez da verdade escapa-lhe às mãos, este ser humano vai se constituindo como autonomia necessitada. Essa necessidade advém como que a necessidade das peças autônomas de um mosaico que perfazem o sentido do todo somente em sua dependência das outras peças, 
entretanto esse mosaico da verdade é, para Benjamin, um mosaico perene, constitui-se nas diversidades que surgiram e continuarão surgindo da origem histórica dos seres humanos ${ }^{10}$. Eis o modo com o qual a Filosofia escapa das determinações absolutas de um sujeito transcendental para Benjamin.

\section{REFERÊNCIAS}

APEL, K -O, "Wittgenstein und Heidegger. Die Frage nach dem Sinn von Sein und die Sinnlosigkeitverdacht gegen alle Metaphysik" In:_ Transformation der Philosophie, vol. 1.

BARRENTO, João. Walter Benjamim: limiar, fronteira e método. Olho d'água Revista do programa de pós-graduação em letras da UNESP, São José do Rio Preto, vol. 4, n. 2, p. 41-51, jul./dez. 2012.

BENJAMIN, Walter. Origem do drama barroco alemão. Trad. Sergio Paulo Rouanet. São Paulo, Brasiliense, 1984.

Passagens. Trad. do alemão Irene Aron - Trad. do francês Cleonice Paes Barreto Mourão. Belo Horizonte: Editora UFMG; São Paulo: Imprensa Oficial do Estado de São Paulo, 2006.

BONACCINI, Juan Adolfo. "Acerca do conceito de fenômeno na Crítica da Razão Pura" in:_Princípios, Ano 04, n 05, 1997. p. 159-186.

CASTRO, Cláudia Maria. "A arte de caçar borboletas". in: Política, cidade, educação: itinerários de Walter Benjamin (Org. JOBIM e SOUZA, Solange e KRAMER, Sônia). Rio de Janeiro: Contraponto, 2009, p. 205 - 217.

D"ANGELO, Martha. Arte, política e educação em Walter Benjamin. São Paulo: Edições Loyola, 2006

GAGNEBIN, J.-M. Do conceito de Darstellung em Walter Benjamin ou verdade e beleza. Kriterion, [on line], 2005, vol. 46, n. 112, p. 183-190, aqui 186. Disponível em: < http://www.scielo.br/scielo> Acesso em: 19 de maio de 2016.

KANT, I. Crítica da razão pura. Trad. Manuela Pinto dos Santos e Alexandre Fradique Morujão. Lisboa: edição Calouste Golbenkian, 1997.

10 "A origem, portanto, não se destaca dos fatos, mas se relaciona com sua pré-história. [...] A categoria da origem não é pois, como supõe Cohen, puramente lógica, mas histórica" (BENJAMIN, 1984, p. 68).

Mestrando em Filosofia no CMAF na Universidade Estadual do Ceará (UECE). Professor de Filosofia do Colégio Christus-CE. Residente em Fortaleza - CE. Email: mardenmoura@hotmail.com 
LOUZADO, Gerson Luiz. "O paradoxo das coisas em si mesmas". In:_o que nos faz pensar no19, fevereiro de 2006, p. 149-164.

MATE, Reyes. Meia-noite na História. Trad. de Nélio Schneider. São Leopoldo: Editora Unisinos, 2011.

MEDEIROS, Mateus Gonçalves de. "Sobre a Crítica do Conhecimento de Walter Benjamin" in:_Cadernos Walter Benjamin, vol. 4, jan./jun. 2010. p. 24-49.

MURICY, K. Alegorias da Dialética. Rio de Janeiro: Relume Dumará, 1999.

PUTNAM, H. "Whi there isn't ready-made word." In:- Realism and reason, philosophical Papers, vol. 3, $7^{\underline{a}}$ ed., Cambridge University Press, 1996. 